\title{
SOCIAL INNOVATIVE POLICIES USING LOCAL KNOWLEDGE TRANSFER: AHP/ANP MODELS FOR THE ROMANIAN COOPERATIVE STRUCTURES
}

\begin{abstract}
In agriculture, non-profit management as a preferable alternative to the public management is regarded as being at the core of the cooperative's integration in the context of both social and market economy. Yet, at least as important as the management, either public or nonprofit, is the legislative edict stating the conditions under which new institutions are founded as well as their administrative composition, financing sources and tasks. This paper comprises the full description of two distinct models built and estimated in the context of the Analytical Hierarchy Processes (AHP) and Analytical Network Processes (ANP) theory. Farmers, representatives from agricultural administrative structures and associations from all the important regions in Romania contributed to the elaboration and estimation of this model, through a program founded by the Regional Network of Rural Development (RNDR). This model is developed with the aim of understanding and quantifying the main risk factors in the optimal design and institutional functioning of the cooperative structures in agriculture and its output constitute one of the most scientific recommendation for a new legislative project. Results refer to a specific optimal distribution of the members, fiscal policies and particular sources of funding. Sensitivity analysis show how various political, social or economic arguments impact on the optimal determination of the main aspects of the cooperatives ' legislative edict .
\end{abstract}

Keywords: Romanian cooperative structures, Analytical Hierarchy Processes, local knowledge transfer, social innovative processes

\section{Introduction}

The innovatory philosophy over the way of defining institutions consists in considering as focal the desired functionalities of the institution to be legally defined. Starting from this conceptual thinking, an integrative view of the institution to be created is developed in relation with the agricultural market and with the rest of the economy. The final conceptual scheme with detailed desired functions for Agricultural Chambers in connection with the social economy and markets is regarded as an example of an innovative social policy.

\section{Data/Model Analysis}

An AHP model for evaluating the risks in the good functioning of the Romanian Agricultural Chambers is briefly indicated below while the ANP model for Cooperatives 
with its synthetized results and sensitivity analysis is skipped for economy of the presentation.

Following the large consultation in two rounds with experts, under the National Network of Rural Development, based on the pilot model presented and after an extended presentation about the history of the development of the RCA and contemporary problems in their good functioning, criterions, sub criterions and alternatives were discussed and finally agreed, together with the correspondent top-down connections.

Few of the results are shown below.

Figure 1. Risk in the good functioning of the Romanian Chambers of Agriculture (RCA)

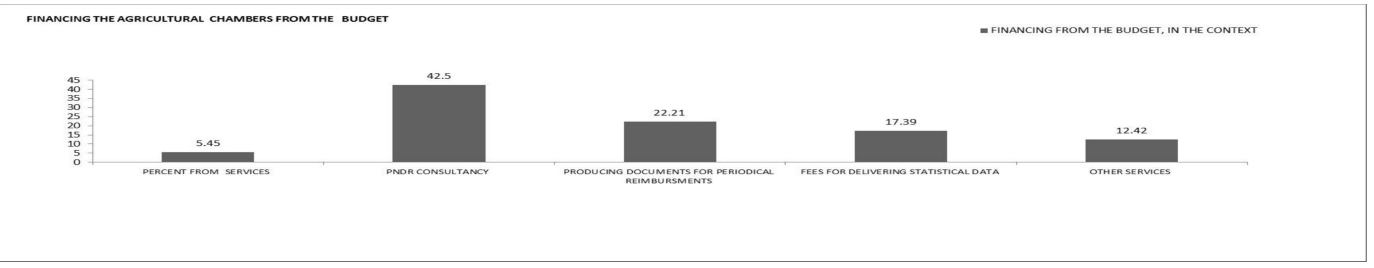

The most attention should be devoted to defining the sources of financing for the Romanian Agricultural Chambers. Since financing proved to be the most important category to be though and afterwards legislated, further are detailed the several sources from the budget for financing, with their corresponding priorities.

Figure 2. The composition of the RCA's as ideally perceived within and outside the AHP context

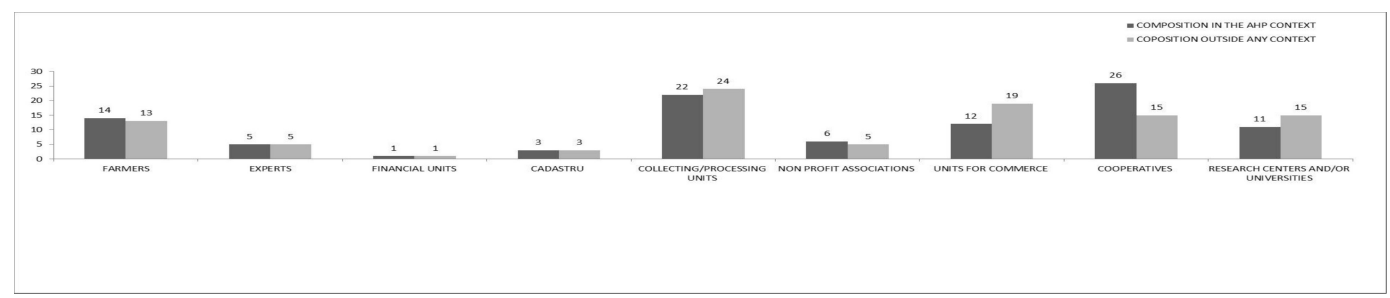

Thus, the most numerous as members should be the agricultural cooperatives, followed by the collecting and processing units. It should be noticed the striking difference in between the number of cooperatives estimated in the AHP context and outside. This comparison is once again emphasizing the importance of judging aspects in the corresponding context.

\section{Conclusions}

Recognizing the specifics of the knowledge transfer, latest developments in the literature bring at the forefront the concept of the local knowledge transfer, with its several important illustrations in the agriculture in several countries. In this stream it is emphasized the importance of including this type of knowledge into the plans and actions of restructuring and modernizing agriculture. This paper brings an important example of the way in which this local knowledge can be included in a rigorous multi-criterial decision model In this sense, the approach tackled is considered to be a social innovative 
ISAHP Article: A Style Guide for Paper Proposals To Be Submitted to the International Symposium on the Analytic Hierarchy Process 2016, London, U.K.

process. The very concrete percentages of importance associated to the diverse sources of financing, both from the budget and from other sources, the number of the members as well as the estimation of the risk factors constitute a valid support for any project aiming to legislate the constituency of these associative structures.

\section{Key References}

1.Bratianu,C., Agapie,Ad., Orzea,I., 2011 Modelling organizational Knowledge Dynamics using Analytic Hierarchy Process" Electronic Journal of Knowledge Management, 9:3, 236-247

2. Bratianu,C., Agapie,Ad., Orzea,I., Agoston,S.. 2013. Knowledge strategies and decision Making, Editura ASE

3. Saaty, T.L. 2010 Principia Mathematica Decernendi Mathematical Principles of Decision Making. Pittsburgh, PA: RWS Publications 